\title{
PRECISE HOLES MACHINING IN MULTI- COMPONENT STACKS FROM METALS AND CFRP
}

\author{
N.S. Chashchin \\ Irkutsk National Research Technical University \\ Irkutsk, Russia \\ rufle54007@mail.ru \\ Y.N. Ivanov \\ Irkutsk National Research Technical University \\ Irkutsk, Russia \\ iv_yuriy@istu.edu
}

\author{
A.E. Pashkov \\ Irkutsk National Research Technical University \\ Irkutsk, Russia \\ pashkov@istu.edu \\ A.A. Sturov \\ Irkutsk National Research Technical University \\ Irkutsk, Russia \\ hero124@yandex.ru
}

\begin{abstract}
The research aims to improve performance of high-accuracy hole-making in hybrid stacks. The stacks consist of carbon fiber reinforced plastic and Titanium and Aluminum alloys. Holes were made with Atlas Copco PFD-1500, a pneumatic drilling machine with automatic tool feeding. A MAPAL hard-alloy six-toothed reamer with MQL channels was used as a cutting tool. Hole diameters were controlled using Carl Zeiss CONTURA G2. Cutting parameters' variation ranges were identified and the experiment was designed in Statistica 6. The experiment design involves two factors (cutting speed, feed) and an additional block factor describing a reaming allowance. As a result, multi-factor regression analysis models were developed. They describe the effects of cutting parameters on the hole accuracy in hybrid stacks. The cutting parameters were optimized and recommendations were given.
\end{abstract}

Keywords - reaming, reamer, hubrid stack, fibre plastic.

\section{INTRODUCTION}

As the machine building industries are developing [1], the demand for high-force materials and their mixes is increasing [2]. Carbon fiber is the most promising material [3]. It is hightensile and flexible, which is not typical of metals [4]. Carbon fiber and metals are connected by bolts and rivets. Holemaking for fasteners is labor intensive as far as stack materials have different machining parameters. For example, Titanium alloys [5] are machined at low cutting speeds, while composite materials - at high ones. Identification of the relationship between the hole [6] accuracy and cutting parameters $[7,8]$ for each layer can help solve these issues [9]. Designing allows using the minimum number of experiments to identify the effects of parameters variation. The method is relevant for machining as far as cutting tool wear influences the hole [10, 11] accuracy and only a decrease in the number of experiments allows conducting the experiment under a wide range of cutting conditions.

\section{EXPERIMENTAL WORK}

\section{A. Research object,cutting tooling and test methods}

A five-layer composite OT4-VT6-CFRP-VT6-Al was a research object. The hole was being made from OT4-side. Figure 1 shows a scheme of the composite stack specifying the thickness of each layer.

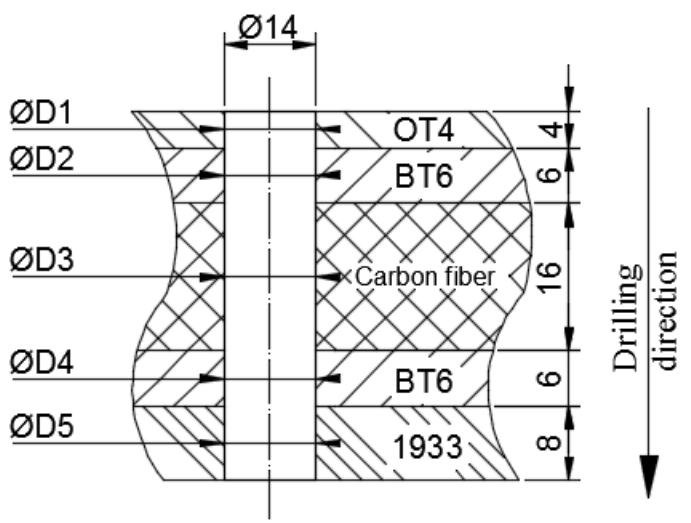

Fig. 1. Scheme of the experimental sample.

The tested tool was a Mapal six-toothed reamer with MQL channels [12].

The experiments were conducted using Atlas Copco PFD1500, a pneumatic drilling machine with automatic tool feeding. The tooling is based on a modular principle which allows for the resetting of cutting parameters by changing units. The cutting parameters $[13,14]$ were varied in a discrete way according to the set blocks. MQL Accu Lube LB 5000 
with a flow rate of $0,5 \mathrm{~g} / \mathrm{min}$ was fed into the cutting area [15, $16]$.

Hole diameters were controlled using Carl Zeiss CONTURA G2 [17]. The diameters [18, 19] were determined for each section in increments of $1 \mathrm{~mm}$ except for transition areas. Deviation from the longitudinal section profile was used as an accuracy parameter.

\section{B. Experiment design}

Cutting speed and feed were used as variables [20]. Natural and standardized variation level values are presented in Table I [21].

TABLE I. NATURAL AND STANDARTIZED DESIGN FACTOR LEVELS

\begin{tabular}{|c|c|c|c|}
\hline Factor & Level-1 & Level 0 & Level 1 \\
\hline $\begin{array}{c}\text { Cutting speed } \\
(\mathrm{m} / \mathrm{min})\end{array}$ & 6,1 & 11,8 & 17,5 \\
\hline $\begin{array}{c}\text { Feed } \\
(\mathrm{mm} / \mathrm{rev})\end{array}$ & 0,16 & 0,27 & 0,38 \\
\hline
\end{tabular}

An additional block factor describing the reaming allowance was used. Allowance values are presented in Table II.

TABLE II. NATURAL AND STANDARDIZED BLOCK FACTOR LEVELS

\begin{tabular}{|c|c|c|}
\hline Unit & Level 1 & Level 2 \\
\hline $\begin{array}{c}\text { Reaming allowance } \\
(\mathrm{mm})\end{array}$ & 0,1 & 0,5 \\
\hline
\end{tabular}

The experiment was designed in Statistica 6 on the basis of the central composite design. The design is not full-factorial, which allows for results without conducting experiments under all cutting parameters. The method is relevant for studying cutting processes as far as an increasing number of operation cycles increases cutting tool wear influencing the results obtained.

Table III shows a composite design matrix.

TABLE III. CENTRAL COMPOSITE DESIGN MATRIX

\begin{tabular}{|c|c|c|c|}
\hline \multirow{2}{*}{$\begin{array}{c}\text { Experiment } \\
\text { number }\end{array}$} & \multicolumn{3}{|c|}{ Standardized factor levels } \\
\cline { 2 - 4 } & $\begin{array}{c}\text { Reaming } \\
\text { allowance (block } \\
\text { factor), X }\end{array}$ & $\begin{array}{c}\text { Cutting } \\
\text { speed, A }\end{array}$ & Feed, B \\
\hline 1 & 1 & 1 & -1 \\
\hline 2 & 2 & -1 & 0 \\
\hline 3 & 2 & 0 & 0 \\
\hline 4 & 2 & 1 & 0 \\
\hline 5 & 1 & -1 & -1 \\
\hline 6 & 2 & 0 & 1 \\
\hline 7 & 2 & 0 & -1 \\
\hline 8 & 2 & 0 & -1 \\
\hline
\end{tabular}

\begin{tabular}{|c|c|c|c|}
\hline \multirow{2}{*}{$\begin{array}{l}\text { Experiment } \\
\text { number }\end{array}$} & \multicolumn{3}{|c|}{ Standardized factor levels } \\
\hline & $\begin{array}{c}\text { Reaming } \\
\text { allowance (block } \\
\text { factor), } \mathrm{X}\end{array}$ & $\begin{array}{l}\text { Cutting } \\
\text { speed, A }\end{array}$ & Feed, B \\
\hline 9 & 1 & 0 & 0 \\
\hline 10 & 2 & 0 & 1 \\
\hline 11 & 2 & 0 & -1 \\
\hline 12 & 1 & -1 & -1 \\
\hline 13 & 2 & 0 & 1 \\
\hline 14 & 1 & 0 & 0 \\
\hline 15 & 1 & 1 & 1 \\
\hline 16 & 2 & 1 & 0 \\
\hline 17 & 1 & 1 & -1 \\
\hline 18 & 1 & 0 & 0 \\
\hline 19 & 1 & -1 & 1 \\
\hline 20 & 1 & 1 & 1 \\
\hline 21 & 2 & -1 & 0 \\
\hline 22 & 1 & -1 & 1 \\
\hline 23 & 1 & 1 & 1 \\
\hline 24 & 1 & -1 & 1 \\
\hline 25 & 1 & 1 & -1 \\
\hline 26 & 2 & 0 & 0 \\
\hline 27 & 2 & -1 & 0 \\
\hline 28 & 2 & 0 & 0 \\
\hline 29 & 1 & -1 & -1 \\
\hline 30 & 2 & 1 & 0 \\
\hline
\end{tabular}

\section{RESULTS}

Factor effects are assessed based on the analysis of variance (ANOVA). Table IV shows the ANOVA results.

TABLE IV. ANALYSIS OF VARIANCE (ANOVA)

\begin{tabular}{|c|c|c|c|c|c|}
\hline Source & SS & Df & MS & F & $\mathrm{p}$ \\
\hline Block & 0.20 & 1 & 1.43 & 0.04 & 0.836187 \\
\hline Speed & 69.13 & 1 & 290.8 & 14.84 & 0.000811 \\
\hline Speed $^{2}$ & 4.46 & 1 & 42.6 & 0.96 & 0.337798 \\
\hline Feed $^{2}$ & 105.49 & 1 & 439.5 & 22.65 & 0.000085 \\
\hline Feed $^{2}$ & 2.84 & 1 & 2.5 & 0.61 & 0.443165 \\
\hline Speed*Feed & 5.64 & 1 & 32.1 & 1.21 & 0.282635 \\
\hline Error & 107.12 & 23 & 11.2 & & \\
\hline Error SS & 299.66 & 29 & & & \\
\hline
\end{tabular}

The most significant factors are those which have errors less than 5\%. These factors are Speed and Feed. To determine model reliability, it is necessary to calculate determination factor $\mathrm{R}^{2}=0.64$.

Using regression analysis, let is calculate the model factors (1).

$\Delta=15.96-0.09$ Block+1.95Speed +0.86 Speed $^{2}$

+2.42 Feed +0.68 Feed $^{2}+0.68$ Speed $^{*}$ Feed

(1) 
Figure 2 shows the relationship between deviations of the longitudinal section profile for all the stack layers and cutting speed and feed. According to the regression analysis results, the influence of the block factor on the profile is minimum. In this case, it is sufficient to study the surface built for one allowance.

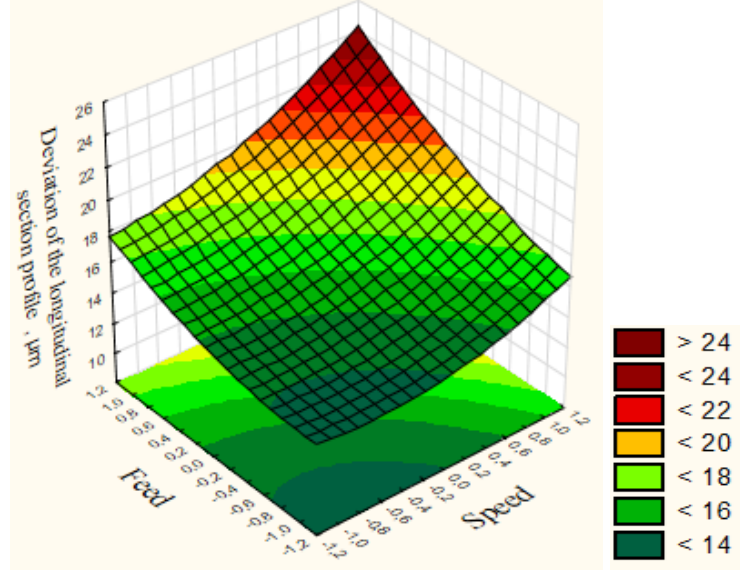

Fig. 2. Deviation of the longitudinal section profile from cutting parameters for all stack layers $(0,1 \mathrm{~mm}$ allowance).

Figure 2 shows that an increase in cutting speed or feed impairs the hole accuracy. For both factors, variations are linear. The maximum deviation value corresponds to the combination of maximum parameters of two factors.

To identify the effects of different materials on the overall deviation profile, it is necessary to analyze each stack layer.

\section{A. Layer OT4.}

Using regression analysis, let us calculate a determination factor $\mathrm{R}^{2}=0.53$ and regression factors. The regression model can be written as:

\section{$\Delta=4+0.68$ Block-1.05Speed-1.03Speed ${ }^{2}+0.21$ Feed- $^{-}$ 0.13 Feed $^{2}-0.56$ Speed $*$ Feed

The model analysis shows that the block factor (reaming allowance) influences the deviation profile. Therefore, it is necessary to build surfaces for each allowance.

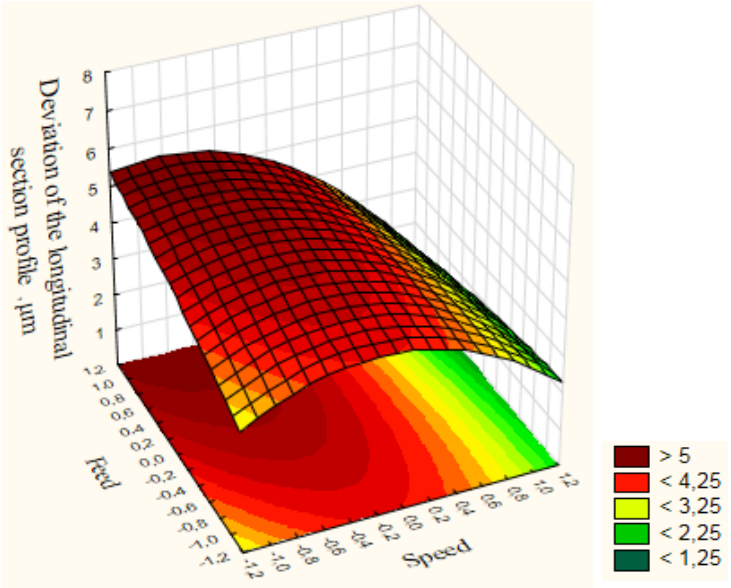

Fig. 3. Deviation of the longitudinal section profile from cutting parameters for OT6 $(0,1 \mathrm{~mm}$ allowance $)$

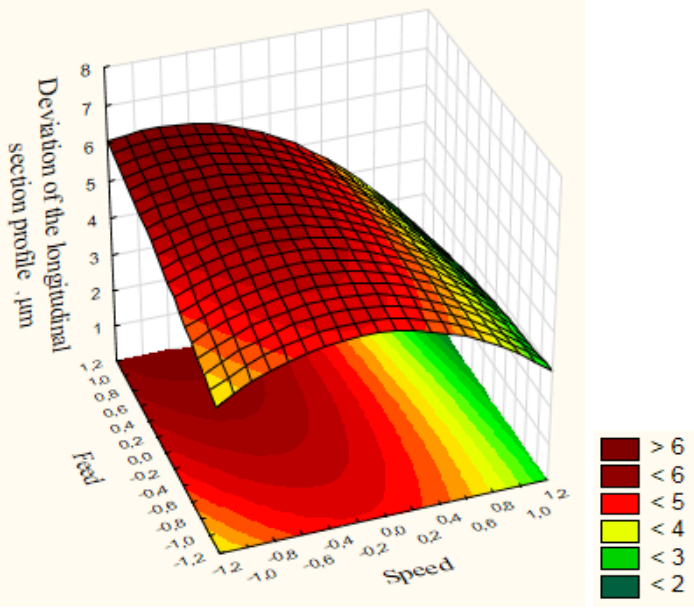

Fig. 4. Deviation of the longitudinal section profile from cutting parameters for OT6 $(0,5 \mathrm{~mm}$ allowance $)$.

Based on the surface analysis, one can conclude that profile deviation variations caused by increasing cutting speed are parabolic. They are maximum at mean speeds and minimum at high ones. An increase in the allowance impairs the hole accuracy.

\section{B. First layer VT6.}

Regression analysis was used to calculate a determination factor $\mathrm{R}^{2}=0.84$ and regression factors. The model for VT6 can be written as:

$$
\begin{gathered}
\Delta=2.86-0.3 \text { Block }+1.66 \text { Speed }+0.01 \text { Speed }^{2}+1.15 \text { Feed } \\
+0.93 \text { Feed }^{2}+1.01 \text { Speed }^{*} \text { Feed }
\end{gathered}
$$

Based on the model analysis, one can conclude that the block factor effect is insignificant. Therefore, it is sufficient to study the surface for one allowance. 


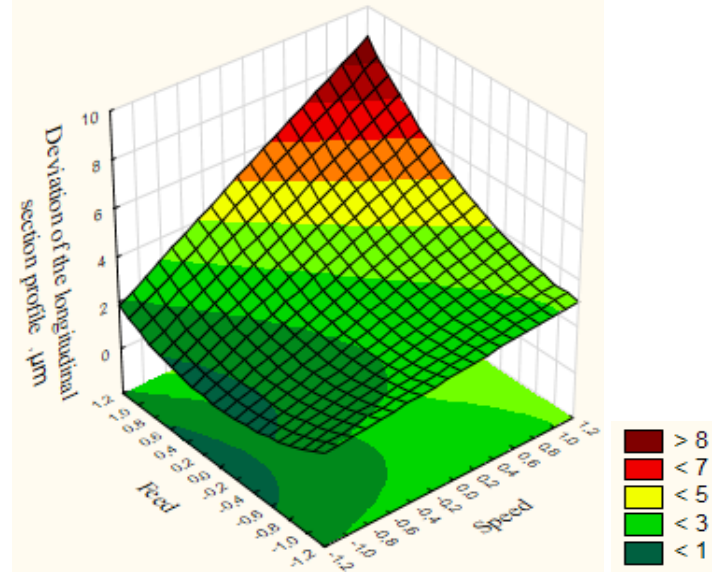

Fig. 5. Deviation of the longitudinal section profile from cutting parameters for VT6 $(0,1 \mathrm{~mm}$ allowance).

Having studied the surface, one can determine that increasing cutting parameters impair the hole accuracy. The maximum accuracy corresponds to minimum cutting speed and mean feed values.

\section{Layer CFRP.}

The determination factor in the CFRP layer is $\mathrm{R}^{2}=0.68$. The model for CFRP can be written as:

$$
\begin{gathered}
\Delta=1.93-0.46 \text { Block }^{2} 0.05 \text { Speed }+0.2 \text { Speed }^{2}+0.64 \text { Feed } \\
+0.42 \text { Feed }^{2}+0.21 \text { Speed } * \text { Feed }
\end{gathered}
$$

Allowance and feed rates have maximum effects on the hole accuracy.

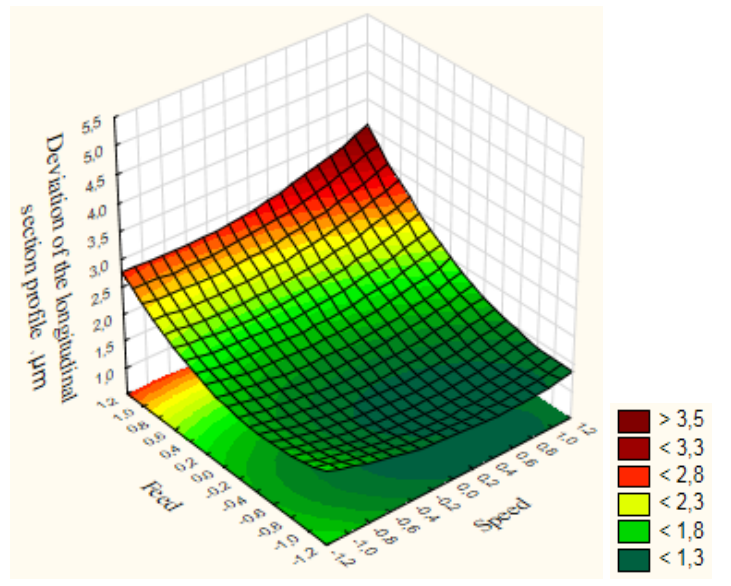

Fig. 6. Deviation of the longitudinal section profile from cutting parameters for CFRP $(0,1 \mathrm{~mm}$ allowance).

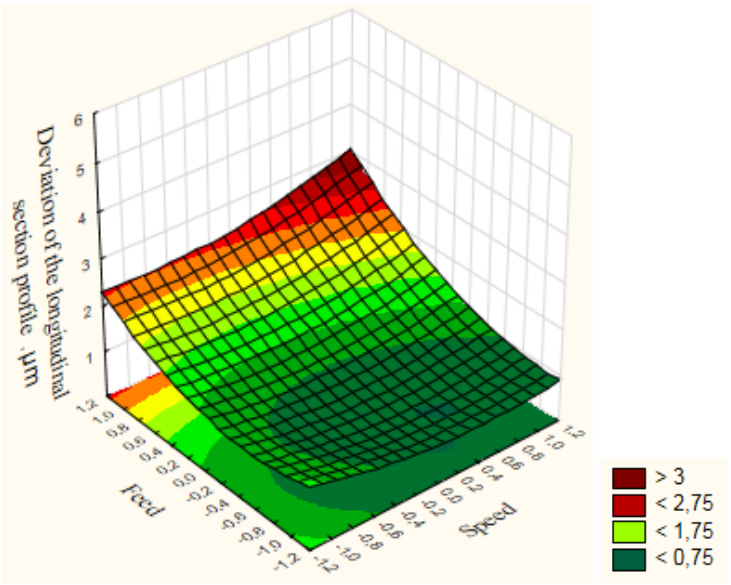

Fig. 7. Deviation of the longitudinal section profile from cutting parameters for CFRP $(0,5 \mathrm{~mm}$ allowance $)$.

Having analyzed the surfaces, one can conclude that an increasing allowance improves the hole accuracy for the CFRP layer. It is due to the fact that at small allowances, the cutting tool crimps carbon fiber rather than cuts it off. After the machining process has been completed, fibers become elastic and decrease the hole diameter.

\section{Second layer VT6.}

In the VT6 layer, the determination factor is $\mathrm{R}^{2}=0.79$. The model can be written as:

$$
\begin{gathered}
\Delta=1.93-0.14 \text { Block }^{2} 1.15 \text { Speed }+0.62 \text { Speed }^{2}+0.1 \text { Feed } \\
+0.26 \text { Feed }^{2}+0.24 \text { Speed } * \text { Feed }
\end{gathered}
$$

Speed and Speed $^{2}$ have a significant effect on the hole accuracy. Therefore, it is sufficient to study the surface for one allowance.

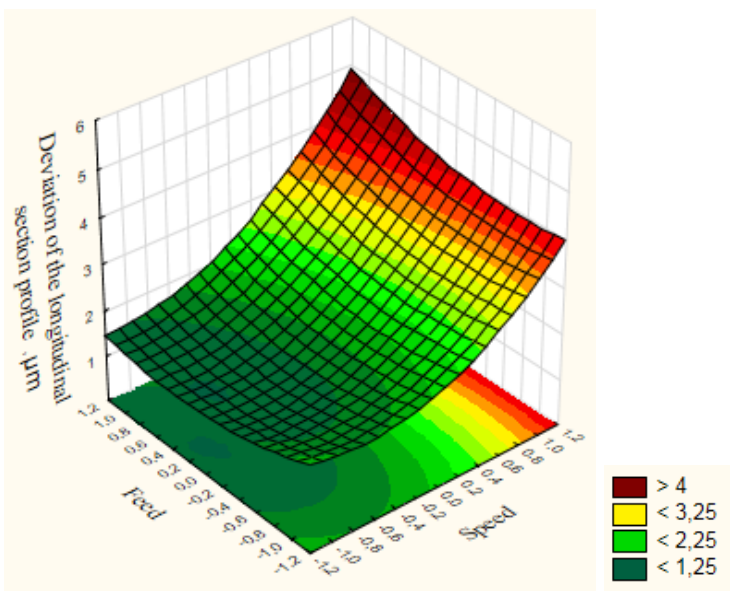

Fig. 8. Deviation of the longitudinal section profile from cutting parameters for VT6 $(0,1 \mathrm{~mm}$ allowance) 
Having studied the surface, one can conclude that feed variation does not influence the hole accuracy, while an increasing cutting speed rate impairs it.

\section{E. Layer Al.}

The determination factor for the $\mathrm{Al}$ layer is $\mathrm{R}^{2}=0.69$. The model can be written as:

$$
\begin{gathered}
\Delta=2.71+0.56 \text { Block }^{+} 0.85 \text { Speed }+0.58 \text { Speed }^{2}+0.59 \text { Feed } \\
+0.62 \text { Feed }^{2}+0.21 \text { Speed } * \text { Feed }
\end{gathered}
$$

Feed and Speed have the least effect on the hole accuracy. All other factors influence the deviation of the longitudinal section profile.

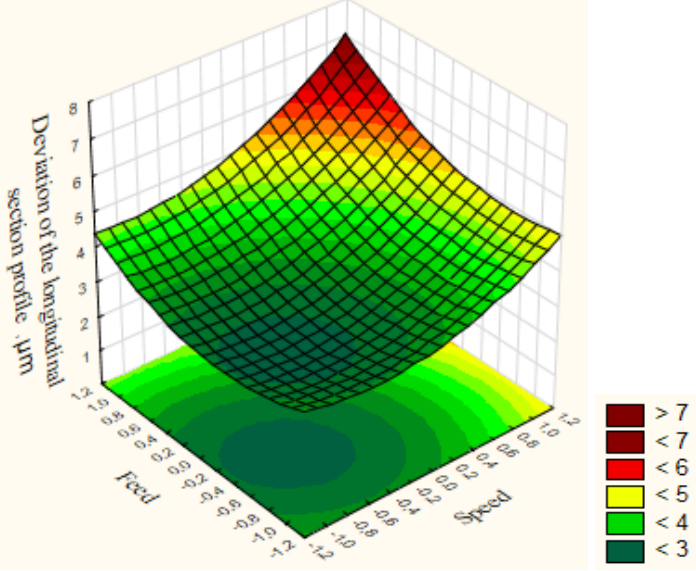

Fig. 9. Deviation of the longitudinal section profile from cutting parameters for $\mathrm{Al}(0,1 \mathrm{~mm}$ allowance $)$

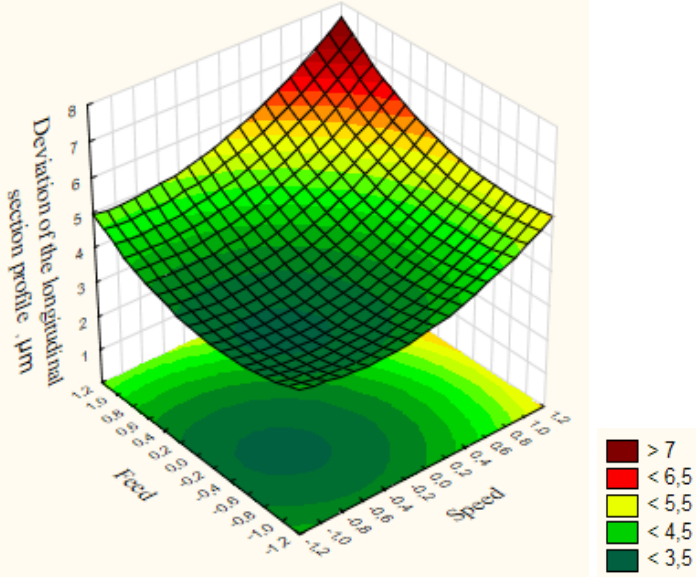

Fig. 10. Deviation of the longitudinal section profile from cutting parameters for $\mathrm{Al}(0,5 \mathrm{~mm}$ allowance)

Having studied the surface, one can conclude that combinations of high cutting speeds and feed impair the hole accuracy. Mean speed and feed values ensure the maximum hole accuracy.

\section{CONCLUSIONS}

1. The models of multi-factor dispersion analysis were built for both hybrid stacks as a whole and each stack layer. The models determine effects of cutting parameters effects on the hole accuracy. Thus, the models can reduce machine time by setting cutting parameters.

2. Among all the stack layers, the first Titanium VT6 and Aluminum layers have a greater effect on deviation of the longitudinal section profile.

3. The most significant factor influencing deviations of the longitudinal section profile is feed. The cutting speed is also a significant factor.

\section{Acknowledgment}

The authors express gratitude to Irkut Corporation for providing with workpiece material tooling and financial and technical support. We are grateful to MAPAL for providing with cutting tools and technical support.

\section{References}

[1] A.A Stepanov, Cutting of high-tensile composite polymeric materials Leningrad: Mashinostroenie, 1987.

[2] V.A. Kolesnik, D.V. Krivoruchko, V.G. Evtukhov, "On microrelief formation for cut surfaces of fiber polymeric composite materials,' Tech-nological systems, vol. 64(3), pp. 60-69, 2013.

[3] Y.A. Vorobyev, A.I. Nikolaenko, A.Y. Vorobyev, "Analysis of researches on drilling hybrid CFRP/Ti stacks," Aerospace machines and technologies, vol 2, pp. 32-38, 2008

[4] C.C. Tsao, "Investigation into the effects of drilling parameters on delamination by various step-core drills," Journal of materials processing technology, vol. 206, pp. 405-411, 2008.

[5] F. Nabhani, "Machining of aerospace titanium alloys," Robotics and Computer-Integrated Manufacturing, vol. 17 (1-2), pp. 99-106, 2001.

[6] D.S. Makashin, Hole accuracy improvement for titanium aero-structure parts using a carbide tool, 2011.

[7] V. I. Drozhzhin, Physical properties and trends of the cutting of layer plastic Thesis, 1983

[8] I. Shyha, S. Leung Soo, D. K. Aspinwall, S. Bradley, S. Dawson, C. J Pretorius, "Key Engineer-ing Materials," vol. 447, pp. 624-633, 2010.

[9] M. N. Islam, N. H. Rafi, P. Charoon, "An Investigation into Effect of Canned Cycles on Drilled Hole Quality," Proceedings of the World Congress on Engineering 2009, vol I, pp. 1-6, 2009.

[10] A. A. Stepanov, Some issues of cutting of high durable composite materials, Potential of cutting structure materials, 1980.

[11] C.-L. Kuo, S. Soo, D. Aspinwall, W. Thomas, C. Carr, D. Pearson, R M'Saoubi, W. Leahy, "Performance of multi-margin coated tools in one-shot drilling of me-tallic-composite stack materials under varying feed rate and pecking conditions," In Proceedings of the 38th International Matador Conference, 2015.

[12] V.I. Lomaev, A.S. Dudarev, "Potential of hole machining during the production of CFRP civil aviation products," Machine building technology, vol. 7, pp. 18-22, 2006

[13] R. Garrick, Drilling Advanced Aircraft Structures with PCD, SAE Technical, 2007.

[14] A. Atarsia, P. Mueller-Hummel, S. Hollenbaugh, "High efficiency in machining carbon fiber composites and metal stacks for aerospace application," Finer Points, vol. 1, pp. 18-28, 2013.

[15] A.A. Pikalov, Peculiarities of hole making in hybrid $\mathrm{KM}-\mathrm{Ti}-\mathrm{Al}$ stacks, Mechanics and machine building, 2012. 
[16] Y.N. Ivanov, E.Y. Kaverzin, A.P. Chapyshev, "Experimental studies of thermal material expansion effects during the dry drilling of holes in CFRP/Ti stacks," Bulletin of Irkutsk State Technical University, vol. 10, pp. 36-42, 2013.

[17] A.A. Spiridonov, Experiment planning when studying engineering processes, Moscow: Machine building, 1981.

[18] V.A. Kolesnik, D.V. Krivoruchko, D. Mital, "Cutting temperature during the drilling of CFRP/Ti stacks," Cutting and tool in engineering systems: International Scientific and Engineer-ing Proceedings. Kharkov: NTU KhPI, vol. 85, pp. 126-136, 2015.

[19] N.S. Chashin, Y.N. Ivanov, "Processing holes in mixed bags by the method of orbital drilling," Irkutsk State Technical University, vol, 11, pp. 44-49, 2015.

[20] X. Rimpault, J.-F. Chatelain, J. E. Klemberg-Sapieha, "Burr height monitoring while drilling CFRP/titanium/aluminium stacks," Phil. Trans. Roy. Soc. London, vol. A247, pp. 529-551, 1955.

[21] Y.N. Ivanov, A.E. Pashkov, N.S. Chashchin, "Optimization of hole generation in Ti/CFRP stacks," IOP Conference Series: Materials Science and Engineering, vol 327, pp. 1-11, 2018. 